\title{
Establishment a Resource Management Program for Accreditation Process at the Medical Laboratory
}

\author{
Sedef Yenice \\ Department of Biochemistry, Gayrettepe Florence Nightingale Hospital, Istanbul, \\ Turkey
}

\section{Introduction}

The Laboratory Accreditation Program from the Joint Commission on Accreditation of Healthcare Organizations (JCAHO) is one of the most widely used CMS-approved accreditation program. The other two accreditation programs are the Laboratory Accreditation Program from the CAP (College of American Pathologists) (http://www.cap.org) and COLA, formerly known as the Commission on Office Laboratory Accreditation (http://www.cola.org). Testing requirements of each organization are at least equivalent to those of CLIA '88, they execute to some extent different testing standards and rationales in reaching the goal of quality laboratory testing. Since 1995, clinical laboratories surveyed using JCAHO standards have been deemed to be certifiable under CLIA ' 88 requirements. The purpose of CLIA '88 is to ensure that all laboratory testing, wherever performed, is done accurately and according to good scientific practices and to provide assurance to the public that access to safe, accurate laboratory testing is available [1]. Joint Commission inspect their members using performance standards that meet or exceed those of CLIA.

The current JCAHO laboratory standards include resource provision and management and mandate that the laboratory leaders plan for and provide adequate resources to meet the mission and goals of the laboratory (Joint Commission of Accreditation of Health Care Organizations, 2009 Accreditation Process Guide for Laboratories: http://www.jcrinc.com/). The areas of resource provision and management include appropriately trained staff; space, utilities, and safety and environmental controls; appropriate equipment and supplies; and adequate systems to handle required information. The planning process by lab leaders needs to address the ability to provide these and other resources, as required. There should also be adequate education to appropriate staff about the quality management system plan and implementation. This communication delineates an execution of resource management (RSM) program and some quality assurance tools that have been developed and tailored in our laboratory to comply with the requirements for laboratory accreditation by Joint Commission International (JCI) [2].

\section{Methods}

The objectives of this work were achieved in accordance with the mission of the hospital, the objectives of our laboratory, any applicable laws or regulations and all relevant accreditation 
standards. The related policies and procedures were developed to provide guidance for workers when implementing the process. The policies were generated based on standard requirements for resource provision and management by JCI [3]. The implementation of this resource management (RSM) program is undertaken in five major sub-fields. Table 1 outlines the descriptions and intents of those pertinent standards classified in each sub-field.

Table 1. Joint Commission International standards regarding resource management.

\section{Standard}

no.

RSM.1 The leaders determine and provide adequate resources, support laboratory employees and to implement, maintain and improve the quality management program.
RSM.2 The clinical director (or leaders) of the laboratory provides an adequate number of qualified staff.
RSM.3 Basic facilities, including adequate space, utilities, and equipment are sufficient for the efficient

\section{Explanation}

After planning for the services provided, the laboratory leaders are responsible for providing adequate, appropriately trained staff and other resources to meet the goals of the laboratory and to meet customer needs. In addition, appropriate resources are provided for the maintenance and improvement of the quality management system. These include the following:

- Staff trained to participate in the program

- Adequate time is allotted for staff to participate in the various aspects of the quality management system, as required by their job responsibilities.

- Information system and data management processes required for the quality management system.

The number and qualifications of all staff, including the director and managers are appropriate to the laboratory's services. Required job qualifications are defined for all laboratory staff positions, as well as job expectations. Required qualifications are at least as stringent as applicable law and regulation. An adequate number of technical and support staff are provided for all required functions. There is also provision for an adequate number of supervisory staff with training and experience to oversee laboratory testing and reporting activities.

The laboratory can provide consistent test results of acceptable quality only when there is provision of appropriate facilities the laboratory environment. These include adequate 


\section{Standard}

no.

Standard

and safe performance of laboratory work.

RSM.4 Laboratory leaders assure that resources required for the provision of services are adequate and available. Such resources include materials required for specimen collection, preparation and processing, examination, and storage, such as

- Laboratory instruments;

- Reagents;

- Consumables; and

- Analytical systems.

RSM.5 The laboratory designs a safe, accessible, effective, and efficient environment consistent with its mission, services, and law and regulation.

\section{Explanation}

buildings, space within the laboratory, appropriate utilities, and supplies and equipment for performance of laboratory tests. In addition, communication systems within the laboratory and between the laboratory and customers are adequate for the size and complexity of the organization, and for the efficient transfer of information and messages.

Adequate resources must be provided for the laboratory to meet goals and customer requirements. The laboratory director is responsible for defining the process of selecting and using equipment, reagents, and other supplies that affect the quality of services. As part of this process, the director defines performance criteria for test methodologies, equipment, and quality control. Criteria are also defined for the inspection, acceptability, and storage of consumable materials.

Laboratory leaders address safety. Adequate safety devices are provided.

\section{Results}

\subsection{RSM.1 - RSM.1.1}

The qualifications and responsibilities of laboratory personnel should include the requirements of CLIA relating to competency assessments in the clinical laboratory [4-6]. The laboratory director and managers and/or other leaders have the appropriate training and experience to perform all responsibilities.

Table 2 and 3 summarize the requirements for laboratory director and technical supervisor, respectively. Those qualifications are described in CLIA'88 under Subpart M - Personnel for Nonwaived Testing §493.1351-\$493.1495. A complete description of the requirement is located at http://www.cms.hhs.gov/clia or http://www.phppo.cdc/clia. 
Ensure that prior to testing patient's specimens, all personnel have the appropriate education and experience, receive the appropriate training for the type and complexity of the services offered, and have demonstrated that they can perform all testing operations reliably to provide and report accurate results.

Ensure that policies and procedures are established for monitoring individuals who conduct pre-analytical, analytical, and post-analytical phases of testing to assure that they are competent and maintain their competency to process specimens, perform test procedures and report test results promptly and proficiently, and whenever necessary, identify needs for remedial training or continuing education to improve skills.

Specify, in writing, the responsibilities and duties of each consultant and each supervisor, as well as each person engaged in the performance of the pre-analytical, analytical, and post-analytical phases of testing. This should identify which examinations and procedures each individual is authorized to perform, whether supervision is required for specimen processing, test performance or result reporting and whether supervisory or director review is required prior to reporting patient test results.

Table 2. Summary of responsibilities of laboratory director

"The technical supervisor is responsible for identifying training needs and assuring that
each individual performing tests receives regular in-service training and education
appropriate for the type and complexity of the laboratory services performed."
"The technical supervisor is responsible for evaluating the competency of all testing
personnel and assuring that the staff maintain their competency to perform test
procedures and report test results promptly, accurately and proficiently. The procedures
for evaluation of the staff must include, but are not limited to-
1. Direct observation of routine patient test performance, including patient preparation,
if applicable, specimen handling, processing and testing.
2. Monitoring the recording and reporting of test results.
3. Review of intermediate test results or worksheets, quality control records, proficiency
testing results, and preventive maintenance records.
5. Direct observation of performance of instrument maintenance and function checks.
internal blind testing samples or external proficiency testing samples.
6. Assessment of problem solving skills."

Table 3. Technical Supervisor Responsibilities

\subsection{RSM.2 - RSM.2.1, 2.2, 2.3, 2.4}

Every individual employed in the laboratory need to be oriented to required duties before being allowed to perform them unsupervised. The orientation program is provided for each employee, regardless of job duties. Employee orientation and competency assessment activities are accomplished through a number of training and measurement of performance once a year [7]. Another reason for performing competency assessment with laboratory personnel is that it is also a requirement of the College of American Pathologist (CAP) for 
accreditation. CAP General Inspection Checklist indicate that the manual that describes training activities and evaluations must be specific for each job description. Those activities requiring judgment of interpretive skills must be included. The records must make it possible for the inspector to be able to determine what skills were assessed and how those skills were measured. Retraining and reassessment of employee competency must occur when problems are identified with employee performance. The training and assessment program must be documented and specific for each job description [8].

The CAP and the JCAHO have guidelines that include several items dealing with initial training and competency assessment of laboratory personnel as a requirement for laboratory certification/accreditation.

Trainings include department policies, job-related tasks, patient safety and Employees Occupational Safety and Health Program (EOSHP). During the first year that an individual is performing such patient testing, competency must be assessed every six months [9-16].

Figure 1 shows a checklist developed in our laboratory to assess the competency of a medical laboratory technician who performs point of care (POC) urinanalysis. Records of documented personnel information including certification or licensure, summary of training and experience, references from previous employers, job description, initial orientation and any retraining, continuing education and achievement, competence evaluations, applicable health records such as immunization status, monitoring for exposure to hazardous chemicals and radiation and untoward incident or accident reports are also maintained for each staff member.

\subsection{RSM.3 - RSM.3.1, 3.1.1, 3.1.2, 3.1.3, 3.1.4, 3.2, 3.3, 3.4, 3.4.1, 3.4.2, 3.4.3}

The laboratory facilities are designed and organized to provide adequate space and allow personnel to perform required work with optimal accuracy, precision, efficiency, timeliness and safety. Specimen collection facilities are designated to respect patient's privacy, security, comfort, and disabilities. In addition, provision is made for optimal specimen collection and/or processing conditions.

Sufficient and appropriate storage space is provided for specimens, reagents, control materials, equipment, laboratory supplies, manuals, slides, histology blocks, and files. Manufacturer or other authoritative storage requirements are met, such as for temperature, ventilation and humidity. Storage areas are kept clean and well maintained. A policy covering security issues concerning patients, visitors, other customers, personnel, and property is established. Equipment (software and hardware), reference materials, consumables, reagents, and analytical systems are safeguarded from adjustments or tampering which would invalidate test results.

Laboratory areas for which space and design should be addressed include areas where clerical functions are performed. Because this function is often critical to reporting the correct result on a patient or maintaining specimen identity, consideration should be given to providing areas where interruptions are uncommon and individuals can give full concentration to the transcriptions or data entry being completed.

One of the fundamental processes is to develop an Employees Occupational Safety and Health Program (EOSHP) to address all types of hazardous materials and wastes in the laboratory [17]. Our EOSHP project was introduced as a reference case and published in the source book entitled "Understanding Health Care Facility Safety" by Joint Commission [18]. The EOSHP puts a system in place that employees have both the right and the need to know about the 


\section{CLINICAL CHEMISTRY LABORATORY \\ EMPLOYEE ORIENTATION/COMPETENCY ASSESSMENT CHECKLIST}

Part 1: Identifying Information (Typed)

DATE:

1. Employee's Name:

2. Position Title: Medical Laboratory Technician

3. Job Description : POC test : UA Multistix/Chemstrip

4. Organizational Location (Dept/Office/Section): Urinanalysis

Part 2: Signatures

\begin{tabular}{|l|l|l|l|}
\cline { 2 - 4 } \multicolumn{1}{c|}{} & Rater's Signature/Date & $\begin{array}{c}\text { Reviewing Official's } \\
\text { Signature/Date }\end{array}$ & Employee Signature/Date \\
\hline $\begin{array}{l}\text { a. Compelencies \& Plam Discussed \& } \\
\text { Developed by Rater \& Employec* }\end{array}$ & & & \\
\hline b. Initial Competencies Assessed & & & \\
\hline c. Progress Review*t & & & \\
\hline d. Final Review** & & & \\
\hline
\end{tabular}

- Signatures Indicate That Expectations Are Understood

**Discussion and Signatures are Required - Narrative is Optional Except When Performance is Uaacceptable

\section{I - INITIAL ORIENTATION (NEW EMPLOYEES)}

A-New Employee Orientation program : The New Employee Orientation program is designed to familiarize new staff members with their jobs, the hospital and work-site environment before an employee begin taboratory work and related other activities. This is a mandatory training requirement for all new employees.

\begin{tabular}{|l|l|l|l|}
\cline { 2 - 4 } \multicolumn{1}{c|}{} & DATE & Training Method & Assessment Method \\
\hline 1. Date attended new employee orientation & & & \\
\hline 2. Date completed departmental orientation & & & \\
\hline 3. On the job orientation and training & & & \\
\hline 4. Evaluate and establish initial competencies & & & \\
\hline
\end{tabular}

B-Position/Job Specific Orientation: Supervisor or designated staff member (preceptor) provides new employee orientation and initial training to his/her job responsibilities, reviews position description, establishes and discusses performance standards, competeneies, behavioral indicators, training requirements, and the performance evaluation process.

Competency Assessment :

1. For initial validation, reads entire Policy/Procedure (SOP)

2. Completes and passes written test (Passing criteria is 100\%)

3. Performs ONE unknown (patient specimens from Clinical Chemistry)

a. Observes universal precautions

b. Checks expiration date of strips

c. Closes vial of strips after removal of strip for test

d. Mixes specimen 10 times by inversion

e. Dips appropriately, blots off excess

f. Matches up strip to reagent pads successfully

g. Differentiales between positive vs negative test results

h. Reads reagent pads correctly - achieves passing yrade on unknown 4. Knows storage requirements of specimen if not immediately dipped and read

5. Understands quality control requirements

1 CRITICAL POINTS - STAFF PLACES INITIALS BY EACH ONE

a. Interfering substances: Glucose- High oncentrations of Vitamin $\mathrm{C}$ (ascorbic acid)

and moderately high amounts of ketones ( $40 \mathrm{mg} / \mathrm{dl}$ ) may cause false negatives for

specimens containing small amounts of glucose (100 mg/dl).

b. QC: Two levels of liquid QC must be run and documented every day.

c. Reading results: Must read pads within indicated times, else blood and glucose may give false positives.

Fig. 1. An employee competency and assessment checklist to assess the competency of a medical laboratory technician who performs point of care (POC) urinanalysis. 
hazards they are exposed to while working and the identities of the chemicals that pose the hazard. It is essential to communicate the hazard information and protective measures required to use these chemicals safely to exposed or potentially exposed employees who may use the chemicals. The implementation of EOSHP incorporates the establishment of a Chemical Hygiene Plan, description of a Hazard Communication Quality Standard (HCQS), development an Employee's Guide to Handle the Hazardous Chemicals to assist the laboratory staff in complying with the EOSHP HCQS, identification of the staff who will be responsible for the initial set up of the EOSHP and the day-to-day activities necessary to comply with each aspect of the HCQS, construction an inventory of all hazardous chemicals used in the laboratory and a written list comprising the hazard descriptions of chemicals. In this respect, guidelines of NFPA (National Fire Protection Association, USA) provide comprehensive source to delineate hazard symbols and classifications [19]. In accordance with the EOSHP HCQS, the Material Safety Data Sheets (MSDS) for the specific hazardous products or chemicals should be supplied. In addition, a guide should be published to explain the terms and definitions in the MSDS. Appropriate signs and labels are prepared as hazard warnings to convey the hazardous effects of the materials. Labeling guidelines are published. Storage conditions and groups are identified for chemical substances. Special areas and cabinets are designated based on the hazard identifications. Safety equipments need to be acquired to ensure the protection of laboratory staff [20]. Guidelines are determined in the event of a chemical spill, incident, or leak from a sealed container. Initial and refresher trainings are provided with all laboratory staff. A copy of the Employee's Guide to Handle the Hazardous Chemicals is handed out as training source document. The primary policies for managing biological hazards should define the mechanisms for oversight for controlling exposures to biological materials in the workplace and include the bloodborne pathogens and exposure plan [21-25]. The related policies and procedures for handling biohazardous materials need to be developed to provide guidance for worker safety when handling or exposure to biological agents and included in the new employee orientation and annual update training programs (Fig. 2) [26,27]. The administration and supervision of patient exposures to and infection with biological agents is the primary responsibility of organization's Infection Control Unit. Assessments of risk for the biological safety management activities are accomplished through a number of audits and data collections on a semi-annual basis. All occupational exposures to or injuries from biological materials are to be reported by employees to the EOSHP coordinator. Biological safety posters including the information, reporting and reduction of exposures to bloodborne pathogens and tuberculosis [28] are posted in all major areas of the laboratory facilities.

A Laboratory Waste Management program should be established to safely control hazardous chemical and biological waste from receipt or generation through use or final disposal in the laboratory. Orientation training must include hazardous waste management (Fig. 3). Chemical waste is characterized as non-hazardous or hazardous in accordance with the rules and regulations specified by OSHA (The federal Occupational Safety and Health Administration, USA) [29,30]. With this regard, a substance, which exhibits one of the four hazardous characteristics (corrosivity, ignitability, reactivity, toxicity), is delineated as Hazardous Chemical Waste. Chemical waste that does not exhibit any of the hazardous characteristics as defined above is considered non-hazardous chemical waste. Any waste that is potentially biohazardous, infectious, or pathological is described as Biological Waste. A Waste Characterization Checklist needs to be developed to determine whether the waste is hazardous or non-hazardous (Fig. 4). 


\section{Bloodborne Pathogen and Other Infectious Agents \\ Record of Training}

\section{Please Print}

Name:

Department \& Division:

Job Title:

Training Date:

Length of Training:

Instructor(s) \& Job Title:

I was informed about:

- the Bloodborne Pathogen Standard;

- the epidemiology and symptoms of bloodborne and other pathogens;

- the mode of transmission of bloodborne and other pathogens;

- the Hospital's exposure control plan;

- a review of the use and limitations of methods that will prevent or reduce exposure, including

- engineering controls;

- work practice controls, and

- personal protective equipment;

- selection and use of personal protective equipment including gloves, gowns and eye protection;

- visual warning of biohazards including labels, signs and color-coded containers;

- information on Hepatitis B Vaccine;

- the procedure to follow if an exposure incident occurs;

- sharps disposal;

- handwashing:

- proper work practices.

This is to certify that the employee named above has completed the above training-

\section{Employee's Signature}

Supervisor's Signature

\section{Date}

\section{Date}

Keep this record for at least three years. Store in Department Office with other training records. This record must be made available upon request by County, Hospital or Environmental Health and Safety Inspectors.

Questions: Call the Biosafety Officer.

Fig. 2. Record of training for bloodborne pathogen and other infectious agents 


\section{Hazardous Waste Generator Record of Training}

\section{Please Print}

Name of Employee:

Department \& Division:

Job Title:

Training Date:

Length of Training:

instructor(s) \& Job Title:

- Use of the EOSHP Hazardous Chemical Waste Management Guidebook

- Hazardous waste definitions

- Labeling of hazardous waste storage containers

- Completion of the waste packing forms

- Contacting the Chemical Waste Manager for waste collection

- Closure of containers

- Container inspections (weekly)

- Secondary containment for free liquid wastes

- Storage of incompatible wastes (separate by tray, cabinet, room, etc.)

- Storage of lead-acid batteries (indoor, curbed, impermeable)

- No hazardous waste allowed in trash or salvage dumpsters

- Who to call for hazardous waste information

- Who to call for approval to sewer non-hazardous chemicals

- Evaporation of chemical residues is not allowed

- Management of problem wastes (unknowns, shock-sensitive, etc.)

- Emergency chemical spill response procedures

- Pollution prevention techniques

- Self auditing procedures

- Other (list):

This is to certify that the employee named above has completed the above training.

Employee's Signature

Supervisor's Signature

$\frac{\text { Date }}{\text { Date }}$

Keep this record for at least three years beyond the termination date of the employee. Store in Department of Human Resources with EOSHP Laboratory Safety - Chemical Hygiene Plan training records. This record must be made available upon request by County. Hospital or Environmental Health and Safety Hazardous Waste Inspectors.

Questions: Refer to your EOSHP Hazardous Chemical Waste Management Guidebook or call the Chemical Waste Manager.

Fig. 3. Hazardous waste generator record of training. Adapted from http://www.dehs.umn.edu/hazwaste_chemwaste_umn_cwmgbk.htm. 


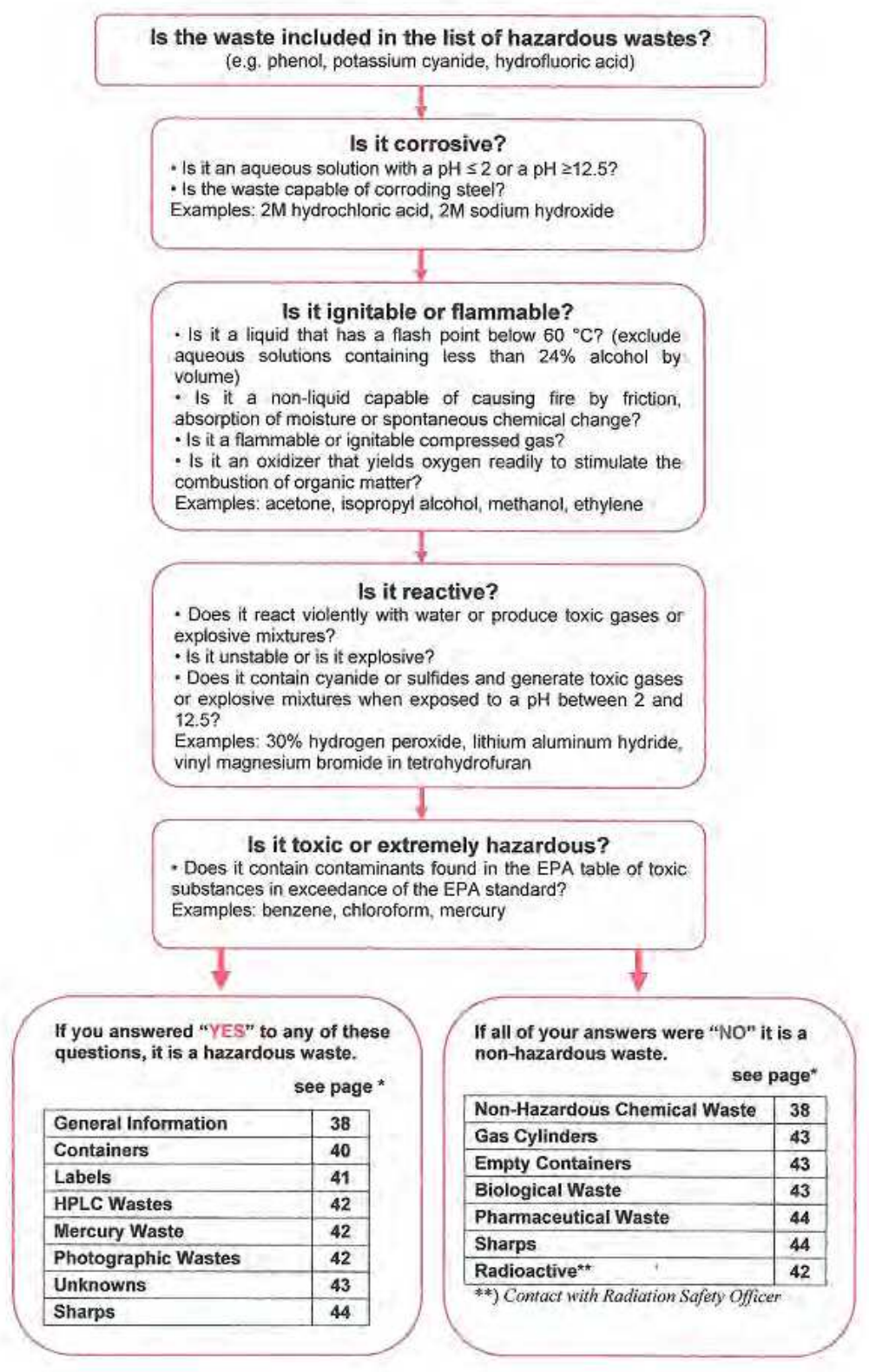

Fig. 4. Waste characterization checklist. Adapted from http://www.uri.edu/safety/old_website/data/LabWasteGuide.pdf.

Policies and procedures for managing and handling radioactive materials and waste should be well defined. The ALARA program [31] and associated work practices are put in practice 
to reduce risks to workers by keeping doses well below the limits. All procedures and practices for radiation safety must comply with law and regulations by the Atomic Energy Authorities.

\subsection{RSM.4 - RSM.4.1, 4.2, 4.3, 4.4, 4.5, 4.6, 4.7, 4.8, 4.9}

The guidelines should be generated to perform initial validation for new instruments and analytical systems to verify that the method(s) will produce accurate and reliable results [3234]. Laboratory instruments and analytical systems are tested upon installation, and prior to use to assure their capability of meeting performance expectations. For new analytical methods, the laboratory verifies, at a minimum, accuracy, precision and the reportable range, as well as confirming that the reference range applies to its patient population. If the laboratory has modified the test or if the method is very complex with many steps, the laboratory also verifies analytical sensitivity and analytical specificity.

The laboratory leaders provide for a program to regularly monitor and demonstrate proper calibration and function of instruments, reagents, and analytical systems. The program also includes preventive assessments through periodic inspection, testing and maintenance for the temperature of water baths, and/or heat blocks, paraffin baths, refrigerators and other temperature dependent equipment, mechanical timers, pipettors and dilutors, volumetric glassware, thermometer and microscopes.

Calibration, calibration verification, function checks, and preventive maintenance are performed on instruments and analytical systems, as needed, and at least according to manufacturers' recommendations. Criteria for calibration verification include at changes of reagent lots; when indicated by quality control data; after major maintenance or service; as recommended by the manufacturer and at least every six months [35]. All required verification checks are documented, along with remedial action when instruments or test methods did not meet performance expectations. A maintenance log for the instruments and analytical systems is kept up to date. Maintenance and inspection ensure that equipment is safe. Equipment is used only by personnel who are competent and authorized to do so.

The historical records are maintained for each instrument. A historical record should include identity of the equipment; manufacturer's name, type identification, and unique identifier such as a serial number; manufacturer's contact person and telephone number, if appropriate; date received and placed into service; current location, where appropriate; condition when received (e.g., new, used, reconditioned); manufacturer's instructions or recommendations, if available, or reference to their location; equipment performance records that confirm the equipment's suitability for use; maintenance carried out to date and what maintenance is planned for the future; damage, malfunction, modification, or repair to the equipment; remedial actions carried out because of unacceptable performance tests.

Detailed records identifying daily, weekly, or monthly performance tests and function checks must be retained for at least two years. Records of major repairs, parts replacement, and semiannual or annual calibration checks and preventive maintenance must be retained for the life of the instrument.

Procedures should be determined to check periodically the validity and quality of reagents and water quality used in laboratory testing. Labeling protocols are defined for all reagents, controls, kits, and solutions. Processes are defined for validating and maintaining computer software and information. 


\subsection{RSM.5 - RSM.5.1, 5.2, 5.3}

Policies and procedures should be developed to provide a safe physical environment where hazards are controlled and personnel activities are managed to reduce the risk of injuries [36]. The details of environmental conditions and supporting safety utilities are represented in Table 4. The laboratory's safety processes should include adequate fire detection and prevention policies. Adequate safety devices such as emergency eyewash, safety cans, puncture-resistant containers for discarding all waste sharps [37], fire extinguishers and blankets are made available and training should be provided to all laboratory staff. Figure 5 presents a laboratory safety self-audit checklist.

Table 4. The details of environmental conditions, supporting safety utilities and tools

Entrances, Exits, Hallways and Stairways

Showers/Eye Operative -

Personal Protective

Equipment

Fire

Extinguisher/Inspection and Location

Pressurized Cylinders
All entrances, exits, hallways and stairways must be clear and unobstructed.

Monthly inspections are required. Any area which deals with corrosive, flammable or otherwise hazardous material is required to have immediate access to eyewash and drench shower facilities. All showers and eye wash equipment must be in full operational order and unobstructed. Eye wash bottles are not adequate equipment.

Personal Protective Equipment such as goggles, masks, gloves and cover gowns must be readily available and not worn outside the immediate work areas. Lab coats and appropriate shoes shall be worn to avoid any contact with harmful materials. Respirators shall be used when applicable. Evidence of respirator training and certification must be readily available.

All fire extinguishers must be inspected monthly. Extinguishers must be properly mounted, unobstructed and be properly labeled for the intended use. Training classes should be offered through the Fire Marshal.

All cylinders must be stored in proper locations. All cylinders must be secured in an upright position and properly restrained to prevent falling. Containers must be labeled for contents and usage. Cylinders of all gases having a Health Hazard Rating of 3 or 4 shall be kept in a continuously mechanical ventilated hood or other ventilated enclosure. Maximum number of cylinders of a flammable gas shall be not more than $3(25 \times 127 \mathrm{~cm}) 45$ square meter in an unsprinkled space or not more than $6(25 \times 127 \mathrm{~cm})$ in a sprinkled space of 45 square meter. Liquefied Gas Cylinders in laboratory work areas shall not exceed 3 cylinders $(23 x$ 
Room Use Identification

Fume Hood Operation

Biological Safety Cabinets

Hazardous Chemicals

Hazardous Waste

Disposal

Equipment and Utility

Labeling

Location of Cut-off

Valves/Circuit Breakers

General Safety (Dress,

Eating, Smoking, etc.) -
$76 \mathrm{~cm})$ in a sprinkled space or exceed 2 cylinders $(23 \times 76 \mathrm{~cm})$ in an unsprinkled space.

All access doors must be marked when rooms or areas are being used for chemical, biological or radioactive purposes as outlined in the Chemical Hygiene Plan. All doors must remain closed and the vision panel must remain unobstructed. Unattended labs shall be locked at all times.

Face Velocities should be between 80 and 120 FPM at the working sash height with an optimum level of 100 FPM. The sash should never be higher than $30 \mathrm{~cm}$ except when accessing equipment. Hoods should not be located in high traffic areas or under air supply vents. The hood must have user spill protection and cup sinks must have spill guards.

Certification is required annually or any time the hood is moved or has had maintenance performed. Cabinets must not be located near high traffic areas or air supply ducts.

All chemicals must be appropriately labeled and shall not be placed near or over floor drains. Flammable liquids must be stored in appropriate containers. 0-35 liter must be stored in shipping containers. 40-75 liter must be stored in specific safety containers, 75 and over must be stored in a safety cabinet.

Hazardous waste training is required for all employees who handle hazardous material.

All utility and plumbing lines need to be labeled and indicate the product contained; i.e., gas, water, etc

All cut off valves and breakers must be properly labeled.

Eating, drinking, smoking and applying cosmetics is not permitted in a wet lab.

Refrigerators, ice machines and microwaves must be labeled for intended use.

Food, personal medication and hazardous materials shall not be housed in the same refrigerator.

Smoking is prohibited throughout all facilities at the organisation (with the exception specially designed 
Use of Flame and Heat

Ventilation

Housekeeping/Drains Flushed

Sharps (Glass, Scalpel, Blades, Syringes, Etc.)

Emergency lighting

Safety Manuals

Accidents

Reported/Investigated

Safety Training Numbers "designated smoking areas"),

Lab Personnel shall not wear loose (e.g. saris, dangling neckties, overly large or ragged lab coats), skimpy (e.g. shorts and/or halter tops), torn clothing, or unrestrained long hair. Perforated shoes, sandals, or cloth sneakers are not to be worn in labs.

No heat generating devices should be left unattended.

Air flow in most labs should be "negative" with respect to the corridor. Laboratory doors shall be kept closed when laboratory procedures are in progress. Volatile hazardous materials shall not be used on the open bench top.

All unnecessary material, boxes, and containers must be disposed of in the appropriate manner. All drains, including floor drains and cup sinks should be flushed with water on a weekly basis to eliminate sewer odors. Proper housekeeping must be maintained to provide adequate clearance of sprinkler systems and emergency equipment.

All sharps, needles and glass must be disposed of in an approved labeled container. Glass containers and other potentially sharp objects shall not be disposed of in common office refuse. Containers must not be overfilled and must be labeled and sealed for proper handling and disposal.

Where necessary, emergency lighting units shall be properly mounted and obstructed. If emergency lighting exists, it should be checked periodically to ensure it is functional.

Emergency Plans/Posted All emergency and contingencies plans and evacuation routes shall be clearly posted in conspicuous places. A list of emergency numbers and contacts must be kept updated and posted alongside the emergency plans.

Manuals must be current and readily available for all employees.

All accidents must be reported to the immediate supervisor for the completion of the appropriate form. File copies of reported incidents and accidents must be on hand, as well as the action taken to alleviate the safety hazard in the future.

This area is designated for either the orientation and annual update training which is required by EOSHP. 


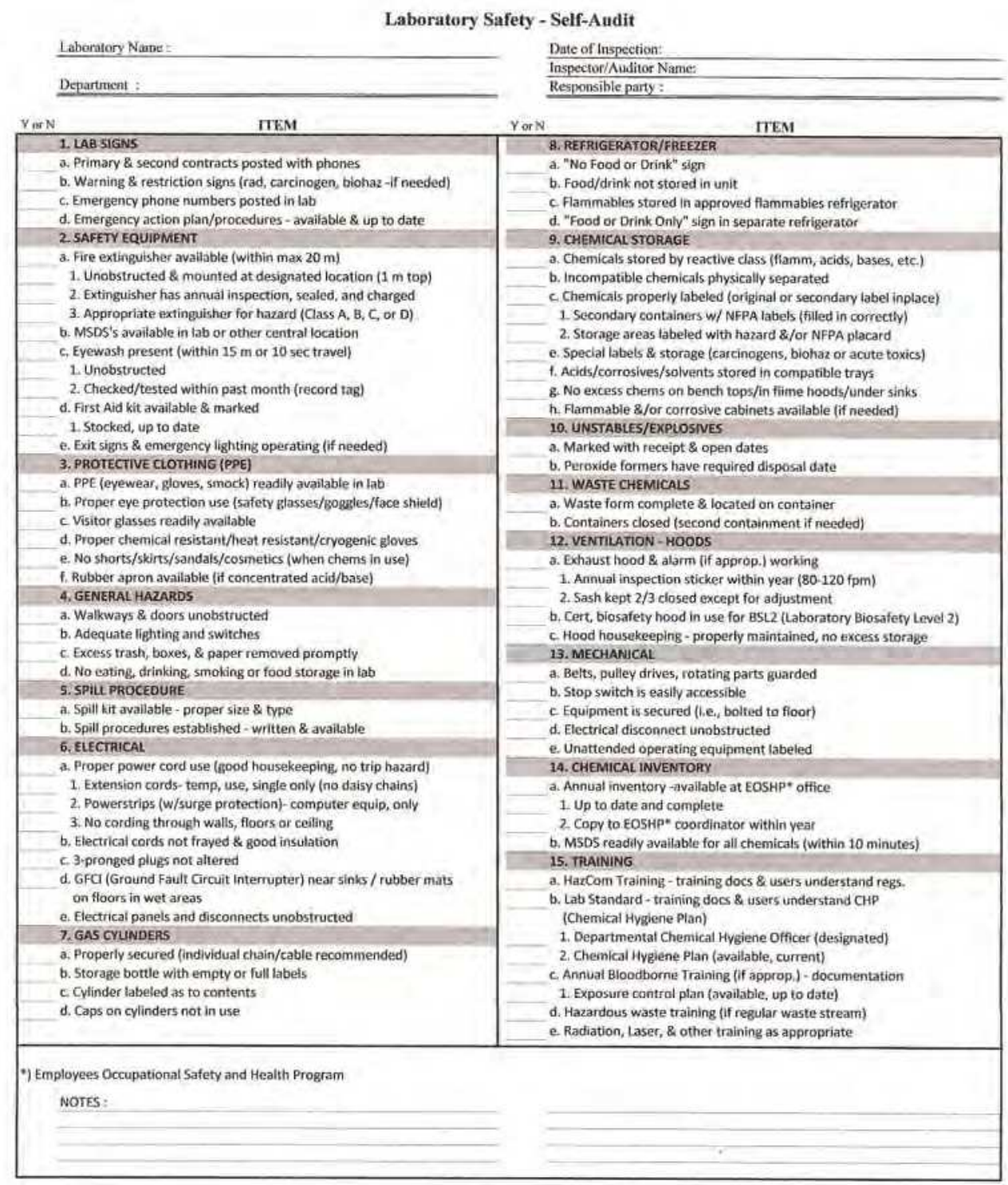

Fig. 5. Laboratory safety self-audit checklist

\section{Conclusion}

Resource management for accreditation process at the medical laboratories applies to many aspects of quality management including personnel, basic facilities, equipment, security and safety. Preparation is key to the success of a resource management program. A 
comprehensive program that includes management commitment, effective training, regular audits of critical functions to identify potential problems, implementation of corrective action and establishment of priorities for improvement benefits the laboratory in many ways.

\section{Acknowledgements}

I thank Coşkun Maden for his kind preparation of the manuscript. The Group Florence Nightingale Hospital Accreditation Fund supported this work.

\section{References}

[1] US Department of Health and Human Services. Clinical Laboratories Improvement Amendments of 1988. Code of the Federal Register, Title 42, part 493. Washington, DC.1988. Available at: http://www.cms.hhs.gov/clia/. Accessed November 16, 2009.

[2] Joint Commission International Accreditation Standards for Clinical Laboratories. $1^{\text {st }}$ ed. Oak Brook Terrace, IL. 2002.

[3] Yenice S. Implementing a resource management program for accreditation process at the medical laboratory. Clinical Biochemistry 2009; 42:266-73.

[4] College of American Pathologists. Criteria for the clinical laboratory director. Appendix O in: Policies and Guidelines Manual. Northfield,IL,1993.

[5] College of American Pathologists. Commission on laboratory accreditation. Laboratory accreditation program. Team Leader Assessment of Director and Quality Checklist. Available at:

http://www.cap.org/apps/docs/laboratory_accreditation/checklists/team_leader _assessment_sep07.pdf. Accessed November 16, 2009.

[6] Code of practice for clinical biochemists (chemical pathologists) and clinical biochemistry services. Available at: http:/ / www.rcpath.org. Accessed November 16, 2009.

[7] National Committee for Clinical Laboratory Standards. 1995. Training verification for laboratory personnel. Approved guideline GP21-A. National Committee for Clinical Laboratory Standards, Wayne, PA.

[8] College of American Pathologists. Standards for laboratory accreditation. Available at: http://www.cap.org/apps/docs/education/competency_assessment/Specific_Ob servation_Checklists.pdf. Accessed November 16, 2009.

[9] Boone DJ. Assessing laboratory employee competence. Arch Pathol Lab Med. 2000;124:190-1.

[10] Howanitz PJ. Employee competence and performance-based assessment: a College of American Pathologists Q-Probes study of laboratory personnel in 522 institutions. Arch Pathol Lab Med. 2000;124:195-202.

[11] McGovern MM, Benach M, Wallenstein S, Boone J, Lubin IM. Personnel standards and quality assurance practices of biochemical genetic testing laboratories in the United States. Arch Pathol Lab Med. 2003;127:71-6.

[12] Sharp SE, Elder BL. Competency assessment in the clinical microbiology laboratory. Clin Micro Rev 2004; 17:681-94. 
[13] Smith BR, Wells A, Alexander CB, et al. Curriculum content and evaluation of resident competency in clinical pathology (laboratory medicine): a proposal. Clin Chem 2006; 52:917- 49.

[14] Hemmer PR, Karon BS, Hernandez JS, Cuthbert C, Fidler ME, Tazelaar HD. Leadership and management training for residents and fellows. A curriculum for future medical directors. Arch Pathol Lab Med. 2007; 131:610-4.

[15] Quality Laboratory Practice and Its Role in Patient Safety: The American Society for Clinical Pathology Policy Statement (Policy Number 06-01).2006.

[16] Joint Commission on Accreditation of Healthcare Organizations. 2008 National Patient Safety Goals Laboratory Services Program. Available at: http://www.jointcommission.org/PatientSafety/NationalPatientSafetyGoals/08_1 ab_npsgs.htm. Accessed November 16, 2009.

[17] Furr AK. CRC Handbook of Laboratory Safety. 4th ed. Boca Raton, Florida: CRC Pres, Inc., 1995.

[18] Working with Hazardous Chemical Materials. In: Understanding Health Care Facility Safety. International Edition. Joint Commission International, 2006. p.149-52.

[19] Available at: http:/ /www.nfpa.org/. Accessed November 16, 2009.

[20] Roder MM. A Guide for evaluating the performance of chemical protective clothing (CPC). Cincinnati, OH, US Department and Health and Human Services Public Health Service Centers for Disease Control and Prevention. 1990.

[21] Primary containment for biohazards: selection, installation and use of biological safety cabinets. 2nd ed. Washington: US Department and Health and Human Services Public Health Service Centers for Disease Control and Prevention. US Government Printing Office; 2000.

[22] Sehulster L, Chinn RYW. Guidelines for environmental infection control in health-care facilities. Recommendations of CDC and the healthcare infection control practices advisory committee (HICPAC). 2003; 52(RR10):1-42.

[23] NCCLS. Protection of laboratory workers from occupationally acquired infections; approved guideline, 3rd ed. Wayne, PA: NCCLS; 2005 (publication no. M29-A3).

[24] Guideline for Hand Hygiene in Health-Care Settings.Recommendations of the Healthcare Infection Control Practices Advisory Committee and the HICPAC/SHEA/APIC/IDSA Hand Hygiene Task Force. Available at http://www.cdc.gov/mmwr/PDF/rr/rr5116.pdf. Accessed November 16, 2009.

[25] Biosafety in microbiological and biomedical laboratories. $5^{\text {th }}$ ed. Washington: US Department and Health and Human Services Public Health Service Centers for Disease Control and Prevention. US Government Printing Office; 2007.

[26] CDC. Exposure to blood: what healthcare personnel need to know. Atlanta, GA: US Department of Health and Human Services CDC; 1999. Available at http://www.cdc.gov/ncidod/hip/BLOOD/Exp_to_Blood.pdf. Accessed November 16, 2009.

[27] CDC. Preventing needlestick injuries in health care settings. Atlanta, GA: CDC; 1999. Available at http://www.cdc.gov/niosh/pdfs/2000-108.pdf. Accessed November 16, 2009.

[28] Mycobacterium tuberculosis: assessing your laboratory. The association of state and territorial public health laboratory directors and US Department and Health and 
Human Services Public Health Service Centers for Disease Control and Prevention. Atlanta, 1995.

[29] Available at: http://www.osha.gov/OshDoc/data_General_Facts/highly-hazardouschemicals-factsheet.pdf. Accessed November 16, 2009.

[30] Available at: http://www.osha.gov/pls/publications/publication.html. Accessed November 16, 2009.

[31] Available at: http://www.ncsu.edu/ehs/radiation/forms/alara.pdf. Accessed November 16, 2009.

[32] Westgard JO. Basic Planning for Quality, Madison, WI: Westgard QC, Inc., 2000.

[33] Westgard JO. Basic Method Validation, 2nd ed. Madison, WI: Westgard QC, Inc., 2003.

[34] Guide to method validation for quantitative analysis in chemical testing laboratories. Irish National Accreditation Board. 2007. Available at: http://www.inab.ie. Accessed March 5, 2008.

[35] College of American Pathologists. Standards for laboratory accreditation. Available at: http://www.cap.org/apps/docs/laboratory_accreditation/lapstandards.pdf. Accessed November 16, 2009.

[36] CDC. Selecting, evaluating, and using sharps disposal containers. Atlanta, GA: CDC; 1998. Available at http://www.cdc.gov/niosh/sharps1.html. Accessed November 16, 2009.

[37] Laboratory risk assessment what, why, and how. US Department and Health and Human Services Public Health Service Centers for Disease Control and Prevention. Atlanta, 1998. 


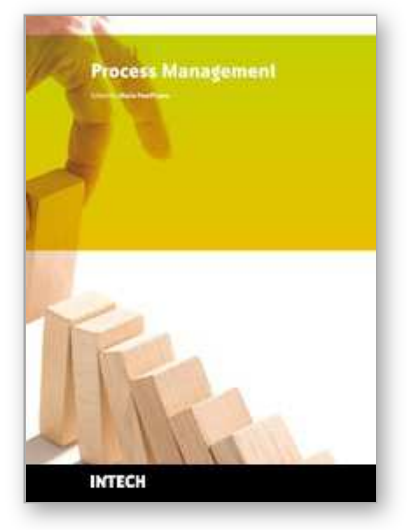

\author{
Process Management \\ Edited by Maria Pomffyova
}

ISBN 978-953-307-085-8

Hard cover, 338 pages

Publisher InTech

Published online 01, April, 2010

Published in print edition April, 2010

The content of the book has been structured into four technical research sections with total of 18 chapters written by well recognized researchers worldwide. These sections are: 1. process and performance management and their measurement methods, 2. management of manufacturing processes with the aim to be quickly adaptable after real situation demands and their control, 3. quality management information and communication systems, their integration and risk management, 4. management processes of healthcare and water, construction and demolition waste problems and integration of environmental processes into management decisions.

\title{
How to reference
}

In order to correctly reference this scholarly work, feel free to copy and paste the following:

Sedef Yenice (2010). Establishment a Resource Management Program for Accreditation Process at the Medical Laboratory, Process Management, Maria Pomffyova (Ed.), ISBN: 978-953-307-085-8, InTech, Available from: http://www.intechopen.com/books/process-management/establishment-a-resourcemanagement-program-for-accreditation-process-at-the-medical-laboratory

\section{INTECH}

open science | open minds

\section{InTech Europe}

University Campus STeP Ri Slavka Krautzeka 83/A 51000 Rijeka, Croatia Phone: +385 (51) 770447

Fax: +385 (51) 686166 www.intechopen.com

\section{InTech China}

Unit 405, Office Block, Hotel Equatorial Shanghai No.65, Yan An Road (West), Shanghai, 200040, China 中国上海市延安西路65号上海国际贵都大饭店办公楼405单元 Phone: +86-21-62489820

Fax: +86-21-62489821 
(C) 2010 The Author(s). Licensee IntechOpen. This chapter is distributed under the terms of the Creative Commons Attribution-NonCommercialShareAlike-3.0 License, which permits use, distribution and reproduction for non-commercial purposes, provided the original is properly cited and derivative works building on this content are distributed under the same license. 